\title{
Laparoscopic fundoplication assisted by robot
}

\author{
Juan Roberto González-Santamaría, María Rubí Valderrama-Gutiérrez, Erick Hiram Rubio Arroyo and Gustavo Alain Flores-Rangel* \\ Advanced center for robotic surgery and minimal invasion, Zumpango's high especialty regional Hospital. Mexico State
}

\begin{abstract}
Introduction: For many years, open fundoplication was the standard for the surgical management of gastroesophageal reflux disease (GERD). In the last two decades, laparoscopic surgery has displaced the open approach by achieving similar results, with a faster convalescence and less postoperative pain. Robotic technology was recently introduced as an evolution of the conventional laparoscopic, whose role is still to be validated.

Material and methods: We describe a retrospective analysis of the initial experience in Nissen floppy-type fundoplications performed by a robot assisted approach in the Zumpango's High Specialty Regional Hospital.

Results: A total of 18 cases were found from June 2014 to December 2017. The total surgical time was 146 minutes (120 to 203), docking time 10.2 minutes (5 to 20) and console time 108.2 minutes (60 to 153). The hospital stay was $39.4 \mathrm{hrs}$ (18 to 192), the perioperative morbidity $11.1 \%$, conversion $5.5 \%$, reoperations $5.5 \%$ and death $0 \%$. At 19.4 months of follow-up, 84.6\% presented remission or improvement of the initial symptoms of GERD (Visick I, II), 15.4\% reported no changes (Visick III), and no patient reported increased symptoms (ViscickIV). The morbidity and conversion of the first 9 cases was $22.2 \%$ and $11.1 \%$ respectively, while in the following 9 cases it was $0 \%$ and $0 \%$.

Discussion: Our initial experience with robot-assisted fundoplications shows comparable results with the reported standards in the medical literature for any approach. The probability of conversion and the incidence of complications are inversely proportional to the accumulated experience, due to the robotic approach requires an aggregate learning curve.
\end{abstract}

\section{Introduction}

GERD is defined as a condition that result from abnormal and recurrentexpositionoftheesophagusand/ortherespiratorytracttogastric contents which generates symptoms or complications, among which are included esophagitis, peptic stenosis, Barrett's esophagus and a diverse number of conditions in the respiratory tract $[1,2]$. It's estimated that in the U.S.A $44 \%$ of the population shows symptoms of pyrosis once per month, $7 \%$ experience it daily, and $20 \%$ of esophagitis is complicated [3]. The management is initially pharmacological in all cases, based on proton-pump inhibitors (PPI), H2 antagonist or anti acids. In relation to tolerance, effectiveness, costs and individual characteristics of each patient, eventually it can be considered a surgical approach, which consists on the making of a gastric plication and represents the therapeutical option with the best long-term results and with a higher satisfaction for the patient $[2,4-6]$.

In 1956 Dr Rudolph Niseen published his procedure designate "fundoplication"(3), later named Nissen fundoplication, which soon would become the standard surgical procedure for the GERD; later Dallemagne and cols performed the first fundoplication by a laparoscopic approach with functional similar results to open surgery, but with a faster convalescence and less post-surgery pain, displacing this way the open approach [6-8]. Nevertheless, the laparoscopic manipulation is hindered by the use of rigid not articulated instruments and a two-dimensional image, besides, the physiological tremors of the surgeon are easily transmitted to the surgical field, which makes dissections and delicate sutures difficult.

Facing this limitations, robotic technology has recently introduced in the clinical laparoscopic practice with the objective of improving surgical performance by eliminating tremors and fatigue, offering a ergonomical pose to the surgeon, allow a tri-dimensional view of the surgery field, granting optic control to the surgeon overcoming the need to coordinate with an assistant, significantly improving the approaching of stitch in complicated places and allowing better maneuverability of the instruments [6].

The performance of robotic assisted fundoplications has proved to be a feasible and safe alternative, with long term results comparable to conventional laparoscopy, although the high cost and surgical time for docking are a challenge for this technology [6,8-11].

\section{Materials and methods}

This is a series of cases that aims to report the initial experience of fundoplications performed by robot-assisted laparoscopic approach in the Zumpango's Regional Hospital of High Specialty and compare the results with those reported in the medical literature.

We retrospectively analyzed the files of all patients undergoing any robot-assisted fundoplication since the acquisition of the robotic surgical system (Da Vinci Si), in a period of time between January 2014 and December 2017.

${ }^{\star}$ Correspondence to: Gustavo Alain Flores Rangel, Zumpango’s High Specialty Regional Hospital. Zumpango-Jilotzingo highway Number 400, Barrio Santiago, Segunda Sección, Zumpango, Estado de México, C.P. 55600, Tel: (591)9177190; E-mail: gustavoflores_@hotmail.com

Key words: reflux, gastroesophageal, GERD, robotic, fundoplication

Received: August 06, 2018; Accepted: August 22, 2018; Published: August 22, 2018 
3 surgeons participated in the performance of the surgeries. The diagnosis of GERD was based on the criteria proposed by the Society of Gastrointestinal and Endoscopic Surgeons of the United States "SAGES" [1].

In all patients with clinical suspicion of GERD a high endoscopy was performed, in case of erosive esophagitis, the diagnosis was concluded without another diagnostic approach. In cases with high clinical suspicion but negative endoscopy, atypical clinical symptoms (dysphagia, odynophagia, weight loss and respiratory conditions) or diagnostic doubt with esophageal motor disorder, $\mathrm{pH}$-metrics and manometry were performed.

The indications for antireflux surgery were patients with good response to management with PPI but reoccurrence of symptoms upon discontinuation, complications of GERD (Barrett's esophagus or peptic stenosis), extraesophageal manifestations of the disease, adequate control of the disease with pharmacological therapy but increased dose or progression of the disease, and some patients with poor response to PPI, particularly those with severe uncontrolled regurgitation or with respiratory symptoms.

In all cases, a Nissen Floppy fundoplication was performed. With general anesthesia, the patient in the supine position, the pneumoperitoneum was performed through a optiview trocar of $12 \mathrm{~mm}$ in the umbilical scar, where the robotic arm of the camera was introduced. It changes to position in Trendelenburg inverted at $30^{\circ}$, trocars are placed under direct vision for two robotic arms of $10 \mathrm{~mm}$ (right and left), one of $5 \mathrm{~mm}$ subxiphoid laparoscopic conventional where Nathanson separator is inserted, and one of $5 \mathrm{~mm}$ in the left (conventional laparoscopic) for retraction, aspiration, irrigation, insertion and extraction of materials. The docking of the da Vinci surgical system was cephalic as shown in Figure 1.

Circumferential dissection of the esophagus was performed, short vessels were sectioned with monopolar energy, closure of the diaphragmatic pillars with two or three simple polyester 2-0 stitch, a $3 \mathrm{~cm}$ fundoplication was made without tension fixed with three simple knots with the same suture and the intermediate anchored to the anterior esophageal wall. Finally the robotic system moves away, materials are removed by laparoscopy and the wounds are sutured.

Three times were recorded: the total surgical time, the robotic docking, and the console time. Prophylactic antibiotic was administered

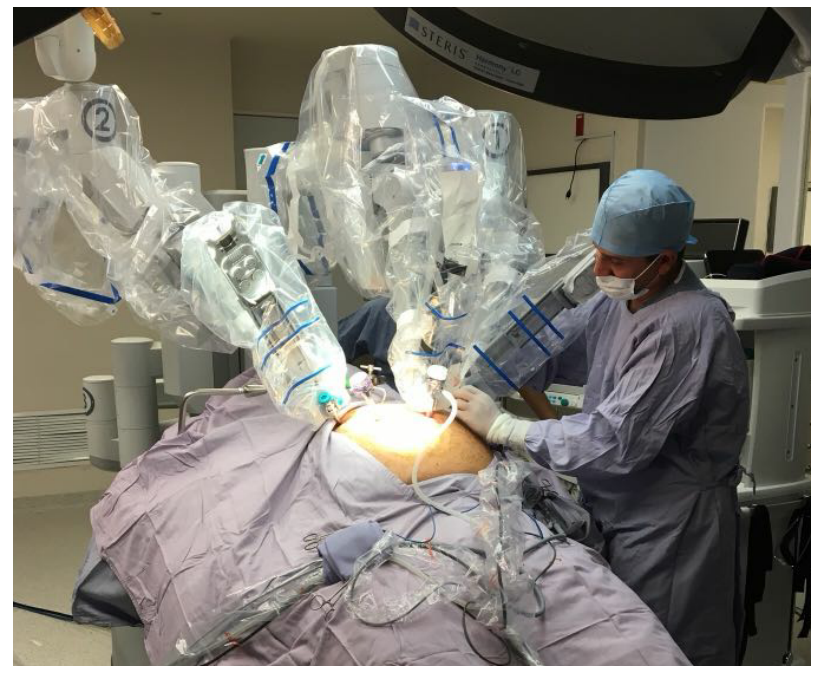

Figure 1. The docking of the da Vinci surgical system with a single dose 30 minutes before the first incision and mechanical / pharmacological antithrombotic measures according to the Caprini scale. After the surgical procedure, a liquid diet was indicated in the first 4 hours with progression according to the patient's tolerance. Conditions for discharge were normal vital signs, tolerance to diet, controlled pain and no evidence of complications.

Long-term follow-up was carried out through telephone surveys using the Visick scale for symptom control and EAT-10 for dysphagia assessment.

\section{Results}

A total of 18 cases were found. The average age was 44.7 years (29 to $71), 10$ patients (55.5\%) were female and $8(45.5 \%)$ male.

$77.7 \%$ of the patients presented esophagitis, being type B in the majority of cases, while $22.2 \%(\mathrm{n}=4)$ corresponded to non-erosive GERD. $22.2 \%$ patients $(n=4)$ presented hiatal hernia (Table 1$)$.

The total surgical time was 146 minutes (120 to 203), 10.2 minutes of docking time (5 to 20 minutes) and 108.2 minutes (60 to 153) of console time. The hospital stay was $39.4 \mathrm{hrs}$ (18 to 192), corresponding to 1.6 days on average.

The perioperative morbidity was $11.1 \%$ ( 2 patients), in one case there was high digestive tract bleeding with spontaneous remission that required transfusion of 2 erythrocyte concentrates, and the second case required conversion to open surgery (5.5\% total incidence of conversion) due to liver injury by the Nathansson separator, with hepatic packing and subsequent reoperation for removal the compresses 48 hours later. They corresponded to a cases number 3 and 6 respectively. If the above is analyzed in 2 periods of time, morbidity and conversion rate in the first 9 cases was $22.2 \% / 11.1 \%$ respectively, and $0 \% / 0 \%$ for the last 9 cases.

For the follow-up, the Viscik and EAT-10 scales were applied, which were achieved in 13 patients $(72.2 \%)$ at 19.4 months on average after surgery. 4 patients (22.2\%) were not located, and 1 patient $(5.5 \%)$ refused to answer the survey. Of the patients interviewed, $84.6 \%(\mathrm{n}=$ 11) presented remission or improvement of the initial symptoms of GERD, while $15.4 \%(n=2)$ did not report differences (Table 2). On the other hand, the incidence of dysphagia was $7.7 \%$ (Table 3 ).

\section{Discussion}

For many years open fundoplication was the standard treatment of gastroesophageal reflux showing good results, been displaced at present by minimally invasive approaches. When a fundoplication is compared by open versus laparoscopic approach assisted by robot, the superiority of the latter is not in doubts; an analysis carried out by the "university consortium of health systems" who evaluated a database of 12,079 patients undergoing fundoplication secondary to GERD, concluded that robot-assisted fundoplication was related to a lower postoperative morbidity (5.6\% vs $11 \%$ ), hospital stay (6.1 days vs 3 days) and costs of care, although the sample of patients undergoing robotic surgery only includes 339 patients [12].

When laparoscopic approach versus assisted by robot are contrasted, most published series agree that robotic surgery usually consumes more surgical time, with total times of 86 to 173 min for conventional laparoscopic, and 137 to 222 for robitic surgery, being maybe due to the time of docking, which has been reported from 5.3 to 23 minutes [6,13-18]. However, this result has been inconstant on the experience of different authors, as the meta-analyzes of Yao et al. [19] and Cundy 
Table 1. Preoperative diagnosis

\begin{tabular}{|l|l|}
\hline DIAGNOSIS & $\mathbf{n}(\mathbf{\%})$ \\
\hline GERD without esophagitis & $4(22.2 \%)$ \\
\hline GERD + esophagitis* & $14(77.7 \%)$ \\
Esophagitis A & $3(16.6 \%)$ \\
Esophagitis B & $8(60 \%)$ \\
Esophagitis C & $3(16.6 \%)$ \\
\hline GERD + esophagitis + Barret & $4(22.2 \%)$ \\
\hline GERD + Hiatal hernia & $4(22.2 \%)$ \\
Type 1 & $1(5.5 \%)$ \\
Type 2 & $2(11.1 \%)$ \\
Type 3 & $1(5.5 \%)$ \\
* Los Angeles Classification & \\
\hline
\end{tabular}

Table 2. Visick score

\begin{tabular}{|c|c|}
\hline I & $5(38.4 \%)$ \\
\hline II & $6(46.1 \%)$ \\
\hline III & $2(15.4 \%)$ \\
\hline IV & 0 \\
\hline Total & $13(100 \%)$ \\
\hline
\end{tabular}

Table 3. Eat-10 score

\begin{tabular}{|c|c|}
\hline Never presented dysphagia & $8(61.5 \%)$ \\
\hline Transient dysphagia* & $4(30.8 \%)$ \\
\hline Persistent dysphagia & $1(7.7 \%) * *$ \\
\hline
\end{tabular}

* They presented postoperative dysphagia, but not currently / **6 points on the EAT-10 dysphagia scale

et al. [20] conclude, where no significant difference was found between the two approaches, or even some authors have achieved a shorter surgical time with the robotic system compared to the conventional laparoscopic, as reported by Müller et al. [21] in a randomized clinical trial ( 88 vs. $102 \mathrm{~min}, \mathrm{p}=0.03$ ).

The truth is that the majority of robot-assisted fundoplication reports have emerged from the initial cases, and it is expected that as the experience increases, surgical time will be reduced, as demonstrated by Heemskerk et al. [16] in a series of 11 patients where in the first 5 cases the time interval between conventional and robot-assisted laparoscopy was 72 minutes in favor of the first, reducing to 27 minutes in the following 6 cases [6]. In another study where the surgical times were analyzed over 2 years and 39 cases, it was concluded that as a greater learning curve is reached, both the docking time and the total surgical time are progressively reduced [18].

Although no study has been designed to specifically evaluate these learning curves, a decrease of $61 \%$ of the surgical time is estimated after the first 5 cases [22].

In the present series of cases, the total surgical time was 146 minutes, despite being an initial casuistry, the results were comparable with the averages reported in the literature for both laparoscopic and robotic surgery.

On the other hand, the average hospital stay is similar regardless of the approach, but widely variable depending on the author's preferences, with a range of $18 \mathrm{hrs}$ ( 0.75 days) to $105.6 \mathrm{hrs}$ (4.4 days) [12-15,17$21,23]$. In the present series, the average hospital stay was $39.4 \mathrm{hrs}(1.6$ days), with a stay in census beds of one night in $89 \%$ of cases.

Some reports of initial experiences have concluded a greater need for conversion in patients with a robot-assisted approach, in figures as high as $11.4 \%$, however, in systematic reviews and meta-analysis where more experienced series are included, there is no difference in the need for conversion between a robotic or laparoscopic approach, being generally less than $3 \%[15,17,19]$. We found the need for conversion on an occasion (5.5\%), corresponding to case number 3, due to a liver injury whit bleeding caused by the hepatic retractor.

On the other hand, when it comes to redo fundoplication, robotic surgery assistance has shown superiority, with lower incidence of conversions to open surgery and shorter hospital stay $[17,24]$.

Perioperative morbidity in general has been reported from $0 \%$ to $5.6 \%[12,18,25]$. In 3 meta-analyzes on the adult population and 1 on pediatrics, general morbidity was reported without significant difference between conventional or robotic laparoscopic approach $[6,14,17,19,20]$. The general probability of reoperations is equivalent, requiring in $5.1 \%$ of the cases and dysphagia being the main cause followed by the recurrence of reflux symptoms [6,12,14,17-19].

Our experience in the first 9 cases was with a high rate of morbidity (22.2\%) and conversion (11.1\%), while in the following 9 cases there was no case, concluding that there is an initial learning curve that must be overcome. It is logical to think that this learning curve must be overcome for any approach, be it open, laparoscopic or robotic.

Most published series conclude that robotic surgery involves a higher cost, although not all authors agree with this statement, such as the meta-analyzes performed by Wang et al. and Yao et al. that included only prospective cohort studies where they concluded that the difference in costs between a conventional laparoscopic and robotic fundoplication does not differ significantly $[6,12-14,17,20,21]$.

When the long-term results are evaluated, the most frequent postoperative complication is dysphagia, with numbers ranging from $1.8 \%$ to $10 \%$, usually with a poor response to endoscopic dilation (up to $25 \%$ ) (27), and without difference between robotic or laparoscopic approach [1,26-28]. The need for antisecretory medication is also similar in the range of $5.6 \%$ to $62 \%$, this wide difference depending on the time of follow-up, being more necessary as the observation period is longer; they generally have a good response to IBP (in the $89 \%$ ) and a good quality of life, with 62 to $97 \%$ satisfaction with the operation in follow-up longer than 5 years; 81 to $92 \%$ referred satisfied with the procedure and willing to do it again (23.30) and 90 to $92 \%$ would recommend the surgery $[2,6,12,17,18,19,23,28-30]$.

The follow-up through the Visick scale has shown acceptable longterm results, with a score of I or II (resolved or improved complaints) between $73 \%$ and $90 \%$ of patients, being more common in order of frequency Visick II (57.4\%), Visick I (21.8\%), VIsick III and IV (9 \%) [18,31-33]. Our results are comparable with $84.6 \%$ of patients with Visick I or II (remission or improvement of symptoms), without any patient viscik IV.

Robot-assisted fundoplication has been a safe and efficient alternative, where the higher cost and surgical time are frequently cited as drawbacks. These statements arise from published experiences with generally modest and initial cases, like this series [22]. The function of these reports should be to determine the learning curves, and not to compare safety and efficiency profiles against other approaches, since this same learning curve represents a considerable bias. It would be expected that improved experience and technology could eventually overcome these disadvantages [34].

\section{Conclusions}

In our initial experience we observed that the probability of conversion and the incidence of complications is inversely proportional to the accumulated experience. 
Despite this learning curve, our results are competitive with the experience reported in the medical literature, both conventional laparoscopic and robot-assisted approaches.

\section{References}

1. [No authors listed] (1998) Guidelines for surgical treatment of gastroesophageal reflux disease (GERD). Society of American Gastrointestinal Endoscopic Surgeons (SAGES). Surg Endosc 12: 186-188. [Crossref]

2. Flores G, Estrada F (2016) Enfermedad por reflujo gastroesofágico. Rev Mex Cir Ap Dig 5: 1-10.

3. Ortiz J (2012) Evolución histórica en el tratamiento de la enfermedad por reflujo gastroesofágico. Cir Endos 13(1): 45-47.

4. Ciovica R, Gadenstatter M, Klingler A, Lechner W, Riedl O, et al. (2006) Quality of life in GERD patients: medical treatment versus antireflux surgery. $J$ Gastrointest Surg 10: 934-939. [Crossref]

5. Anvari M, Allen C, Marshall J, Armstrong D, Goeree R, et al. (2006) A randomized controlled trial of laparoscopic nissen fundoplication versus proton pump inhibitors for treatment of patients with chronic gastroesophageaGl reflux disease: Oneyear followup. Surg Innov 13: 238-249. [Crossref]

6. Wang Z, Zheng Q, Jin Z (2012) Meta-analysis of robot-assisted versus conventional laparoscopic Nissen fundoplication for gastro-oesophageal reflux diseaseans. ANZ J Surg 82: 112-117. [Crossref]

7. Dallemagne B, Weerts JM, Jehaes C, Markiewicz S, Lombard R (1991) Laparoscopic Nissen fundoplication: preliminary report. Surg Endosc 1: 138-143. [Crossref]

8. Heemskerk J, Van Gemert WG, Greve JWM, Greve JW, Bouvy ND (2007) Robotassisted versus conventional laparoscopic Nissen fundoplication: A comparitive, retrospective study on costs and timeconsumption. Surg Laparosc Endosc Percutan Tech 17: 1-4. [Crossref]

9. Strate U, Emmermann A, Fibbe C, Layer P, Zornig C (2008) Laparoscopic fundoplication: Nissen versus Toupet two-year outcome of a prospective randomized study of 200 patient regardin preoperative esophageal motility. Surg Endosc 22: 21-30. [Crossref]

10. Schiefke I, Zabel-Langhennig A, Neumann S, Feisthammel J, Moessner J, et al. (2005) Long term failure of endoscopic gastroplication (EndoCinch). Gut 54: 752-758. [Crossref]

11. Huerta-Iga F, Tamayo-de la Cuesta JL, Noble-Lugo A, Hernández-Guerrero A, TorresVillalobos G, et al. (2013) [The Mexican consensus on gastroesophageal reflux disease. Part II]. Rev Gastroenterol Mex 78: 231-239. [Crossref]

12. Owen B, Simorov A, Siref A, Shostrom V, Oleynikov D (2014) How does robotic antireflux surgery compare with traditional open and laparoscopic techniques: a cost and outcomes analysis. Surg Endosc 28: 1686-1690. [Crossref]

13. Morino M, Pellegrino L, Giaccone C, Garrone C, Rebecchi F (2006) Randomized clinical trial of robot-assisted versus laparoscopic Nissen fundoplication. Br J Surg 93: 553-558. [Crossref]

14. Markar SR, Karthikesalingam AP, Hagen ME, Talamini M, Horgan S (2010) Robotic vs. laparoscopic Nissen fundoplication for gastro-oesophageal reflux disease: systematic review and meta-analysis. Int J Med Robot 6: 125-131. [Crossref]

15. Nakadi IE, Mélot C, Closset J, DeMoor V, Bétroune K, et al. (2006) Evaluation of da Vinci Nissen fundoplication clinical results and cost minimization. World J Surg 30: 1050-1054. [Crossref]

16. Schiefke I, Zabel-Langhennig A, Neumann S, Feisthammel J, Moessner J, et al. (2005) Long term failure of endoscopic gastroplication (EndoCinch). Gut 54: 752-758. [Crossref]
17. Rebecchi F, Allaix ME, Morino M (2017) Robotic technological aids in esophageal surgery. J Vis Surg 3: 7. [Crossref]

18. Jensen JS, Antonsen HK, Durup J (2017) Two years of experience with robot-assisted anti-reflux surgery: A retrospective cohort study. Int J Surg 39: 260-266. [Crossref]

19. Yao G, Liu K, Fan Y (2014) Robotic Nissen fundoplication for gastroesophageal reflux disease: a meta-analysis of prospective randomized controlled trials. Surg Today 44: 1415-1423. [Crossref]

20. Cundy TP, Harling L, Marcus HJ, Athanasiou T, Darzi AW (2014) Meta-analysis of robot-assisted versus conventional laparoscopic fundoplication in children. $J$ Pediatr Surg 49: 646-652. [Crossref]

21. Müller B, Reiter M, Wente M, Bintintan V, Köninger J, et al. (2007) Robot-assisted versus conventional laparoscopic fundoplication: short-term outcome of a pilot randomized controlled trial. Surg Endosc 21: 1800-1805. [Crossref]

22. Antonio Luiz de Vasconcellos Macedo, Wagner Marcondes, Bernardino Tranches Junior, Flavio Steinwur (2017) Secrets for successful laparoscopic antireflux surgery: robotic surgery. Ann Lap Surg 2: 1-4.

23. Prieto E, Medina J, Brizuela C, González M, Mellín T, et al. (2014) Patient satisfaction and quality of life following laparoscopic Nissen fundoplication. Rev Gastroenterol Mex 79: 73-78. [Crossref]

24. Tolboom RC, Draaisma WA, Broeders IA (2016) Evaluation of conventiona laparoscopic versus robot-assisted laparoscopic redo hiatal hernia and antireflux surgery: a cohort study. J Robot Surg 10: 33-39. [Crossref]

25. Spechler SJ, Lee E, Ahnen D, Goyal RK, Hirano I, et al. (2001) Long-term outcome of medical and surgical therapies for gastroesophageal reflux disease: follow-up of a randomized controlled trial. JAMA 285: 2331-2338. [Crossref]

26. Raña RG (2011) Efectos adversos y falla a los inhibidores de la bomba de protones (IBP) 2010. Rev Gastr Méx 1: 49-52.

27. Braghetto IM, Korn OB, Valladares H, Silva JC, Aazabache V (2010) Indications of antireflux surgery: Good and bad candidates for surgery? Bibliographic review and personal experience. Rev Med Chile 138: 605-611.

28. Schwartz Principles of surgery.9na ed. Mc Graw Hill. Cap 25 Esophagus and diaphragmatic hernia.

29. Katz PO, Gerson LB, Vela MF (2013) Guidelines for the diagnosis and management of gastroesophageal reflux disease. Am J Gastroenterol 108: 308-328. [Crossref]

30. Vidal O, Lacy A, Pera M, Valentini M, Bollo J, et al. (2006) Long-term Control of Gastroesophageal Reflux Disease Symptoms After Laparoscopic Nissen-Rosetti Fundoplication. J Gastrointest Surg 10: 863-869. [Crossref]

31. Rijnhart-De Jong HG, Draaisma WA, Smout AJ, Broeders IA, Gooszen HG (2008) The Visick score: a good measure for the overall effect of antireflux surgery? Scand $J$ Gastroenterol 43: 787-793. [Crossref]

32. Zsolt S, Paszt A, Géczi T, Abrahám S, Tóth I, et al. (2014) Comparison of surgical patients with gastroesophageal reflux disease and Barrett's esophagus. Magy Seb 67 287-296. [Crossref]

33. Pessaux P, Arnaud JP, Ghavami B, Flament JB, Trebuchet G, et al. (2000) Laparoscopic antireflux surgery: comparative study of Nissen, Nissen-Rossetti, and Toupe fundoplication. French Society of Laparoscopic Surgery. Surg Endosc 14: 1024-1027. [Crossref]

34. Pushdary K (2013) Is there a Future for Robot-assisted Laparoscopic Nissen Fundoplication (RALF)? World Jour Lap Surg 6: 19-22.

Copyright: (C2018 González-Santamaría JR. This is an open-access article distributed under the terms of the Creative Commons Attribution License, which permits unrestricted use, distribution, and reproduction in any medium, provided the original author and source are credited. 